\title{
Measurement of protein flux with positron emission tomography in neonates
}

Vijay Nama, Jim K Kozlowski, Aaron Hamvas

\begin{abstract}
Aim-To determine whether abnormal transvascular protein flux can be measured with positron emission tomography (PET) in neonates with respiratory distress syndrome (RDS).

Methods-Fourteen infants with normal gas exchange (non-RDS group) underwent one PET measurement and 12 infants with RDS (the RDS group) underwent two measurements of protein flux, as determined by the pulmonary transcapillary escape rate for ${ }^{68}$ Gallium labelled transferrin (PTCER).

Results-The mean PTCER for the RDS infants $\left(132 \pm 3910^{-4} / \mathrm{min}\right)$ was significantly greater than that for infants without RDS $\left(75 \pm 2710^{-4} / \mathrm{min}\right)$. PTCER did not change between measurements in the infants with RDS, including five who received and responded to surfactant replacement between the two scans.

Conclusions-Increased transvascular flux of large molecular weight proteins complicates RDS in preterm infants. PET provides a tool with which to evaluate the processes that contribute to pulmonary dysfunction in neonates.

(Arch Dis Child Fetal Neonatal Ed 1999;80:F26-F29)
\end{abstract}

Keywords: respiratory distress syndrome; positron emission tomography; pulmonary vascular permeability

Respiratory distress syndrome (RDS) in premature infants is caused by interacting pathophysiological processes which include alveolar collapse, ventilation-perfusion mismatch, and accumulation of extravasated proteins and water in the alveolar space. ${ }^{1}$ Invasive studies in preterm lambs with RDS have shown enhanced protein flux through a disrupted endothelial-alveolar epithelial barrier. ${ }^{2}$ However, the lack of non-invasive, quantitative methods has limited the evaluation of protein flux in human neonates. The only in vivo study in neonates showed rapid clearance of an inhaled low molecular weight tracer, diethylene-triamine penta-acetate (DTPA, molecular weight 492 Daltons), from the lungs of infants with RDS, suggesting a disrupted alveolar epithelial barrier. ${ }^{4}$ None the less no in vivo human studies have estimated the flux of larger molecular weight proteins from the intravascular space into the extravascular space in preterm infants with RDS.

Using the nuclear medicine imaging technique of positron emission tomography (PET), the transvascular flux of transferrin, a protein with a molecular weight (79 550 Daltons) similar to albumin (69 000 Daltons), is increased in adults with the acute respiratory distress syndrome (ARDS)..$^{5-7}$ Furthermore, ${ }^{18}[\mathrm{~F}]$ fluorodeoxyglucose uptake, a marker for neutrophil activity, was increased in PET studies of acute lung injury in newborn piglets undergoing high pressure ventilation. ${ }^{8}$ The success of PET in the assessment of pulmonary dysfunction in adults and the correlation between structure and function in animal studies prompted us to determine if PET could be used to detect increased protein flux in human neonates with RDS. ${ }^{9}{ }^{10}$

\section{Methods}

Infants were recruited from the neonatal intensive care unit at St Louis Children's Hospital. Two groups of infants were studied: non-RDS $(\mathrm{n}=14)$ comprising term or preterm infants with a normal respiratory rate, normal chest radiograph, and peripheral oxygen saturations $>94 \%$ while breathing ambient air; and those with RDS ( $n=12)$, comprising preterm infants who required supplemental oxygen to maintain peripheral oxygen saturations $>94 \%$, and who had chest radiographs with diffuse granular infiltrates. No infants had positive blood cultures or a clinically detectable patent ductus arteriosus (PDA) at the time of the measurements. Two mothers received antenatal corticosteroids, one in the non-RDS group and one in the RDS group. The non-RDS infants underwent one PET scan within the first 4 days of life. In an effort to decrease the possible influences of longer term mechanical ventilation on the PET physiological measurements, all but two RDS infants underwent two PET scans at least 6 hours apart within the first 24 hours of life. Five infants received surfactant replacement between the two scans.

Informed consent was obtained from the parents, and permission was obtained from the bedside care providers. Historical and clinical data were obtained from the mothers' and infants' records. The protocol was approved by the Washington University Human Studies Committee and the Washington University Radioactive Drug Research Committee.

PET scans were performed at the Washington University Clinical PET Facility under medical and nursing supervision. A Siemens $953 \mathrm{~B} / 47$ high resolution tomograph $(6 \mathrm{~mm}$ in-plane resolution and $3 \mathrm{~mm}$ slice thickness) was used for all measurements. The infant was placed supine with the thorax positioned in the middle of the field of view. Attenuation correction was determined for each subject by obtaining a 10 minute transmission scan with an external ring source of ${ }^{68}$ Germanium${ }^{68}$ Gallium. 


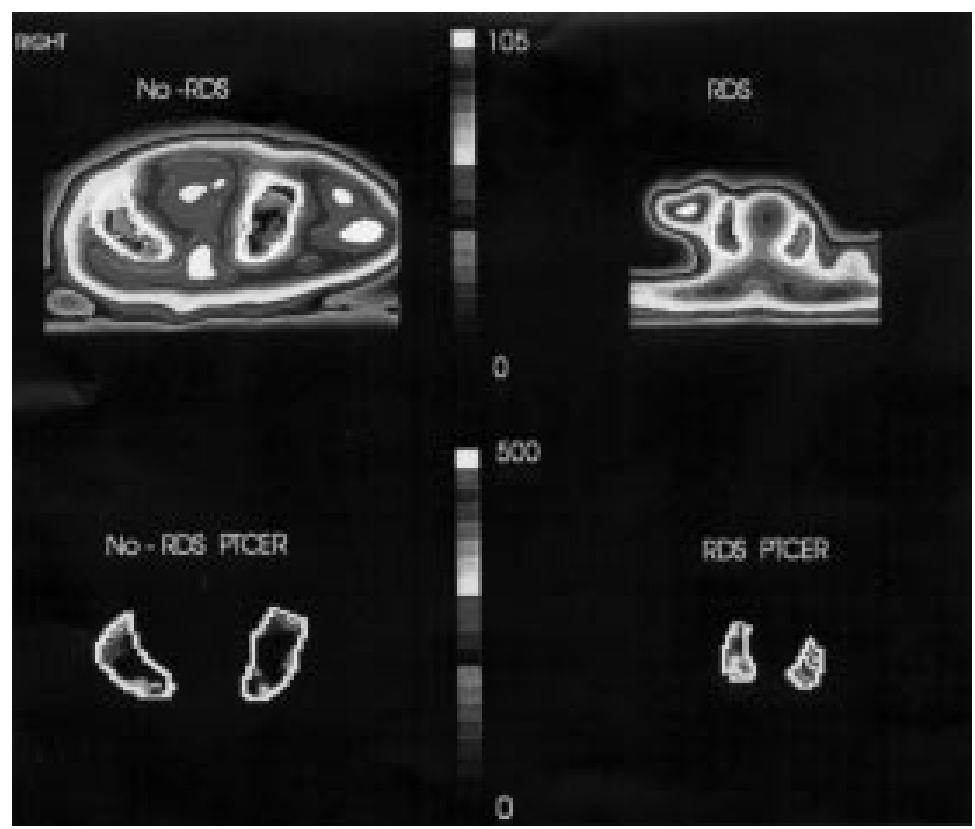

Figure 1 Representative transverse PET images of a transmission scan (top row) and pulmonary vascular permeability (PTCER, bottom row) in infant without RDS (left hand panels) and an infant with RDS (right hand panels). The infant is supine, with the right side on the left of the image. The difference in size between the two images reflects the smaller size of the preterm RDS infant. Brighter areas represent greater protein flux in the PTCER image. PTCER values on the right and left sides were 27 and $3110^{-4} / \mathrm{min}$ for infant without RDS and 274 and $27910^{-4} / \mathrm{min}$ for the RDS infant.

Permeability was measured after intravenous injection of 35 microCurie $/ \mathrm{kg}$ of ${ }^{68} \mathrm{Gallium}$ $\left({ }^{68} \mathrm{Ga}\right)$ citrate. This dose provides an effective radiation dose equivalent (EDE) of 189 mrem. (For comparison, annual background radiation in St Louis is 300 mrem per year, a standard nuclear renal scan using ${ }^{99 \mathrm{~m}}$ Technetium provides an EDE of 230 mrem, and a computed tomogram of the chest provides an EDE of $1000 \mathrm{mrem})$. The ${ }^{68} \mathrm{Ga}$ binds rapidly to native transferrin and has a molecular radius and permeability properties similar to that of albumin. ${ }^{11}$ Serial emission scans were obtained for 30 minutes, beginning 2 minutes after tracer injection. The tracer activity within the cardiac blood pool and the lungs was measured

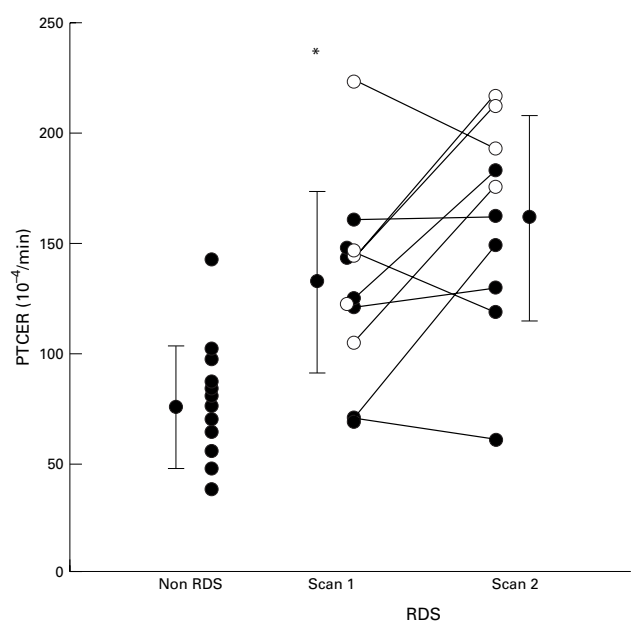

Figure 2 Plots of individual and mean (SD) PTCER values for non-RDS and RDS infants. * Mean PTCER for scan 1 for infants with RDS was significantly greater than that for those without $(p=0.001)$, but not different from scan $2(p=0.07)$. Open circles represent infants who received surfactant replacement between scans. on each emission scan. Subsequently, timeactivity curves were constructed from the blood and tissue measurements and were analysed with a two compartment mathematical model. From this model, a rate constant, k1, for flux of labelled transferrin from the intravascular to the extravascular compartment was calculated. ${ }^{12}$ Because protein flux is affected by surface area available for exchange, k1 was normalised for regional blood volume, which is an approximation of the microvascular surface area. Regional blood volume is calculated from the distribution of activity in the first minutes after tracer injection, when virtually all tracer activity is in the intravascular compartment. ${ }^{12} 13$ This volume normalised rate of protein flux is a measure of pulmonary vascular permeability, termed the pulmonary transcapillary escape rate (PTCER) for ${ }^{68} \mathrm{Ga}-$ labelled transferrin, and is expressed in units of $10^{-4} / \mathrm{min}$

To analyse the PET data, regions of interest were defined within the lung fields on multiple tomographic slices of the transmission scan (fig 1). In defining the regions of interest, care was taken to avoid the heart, surrounding major vessels, and chest wall. The regions were then superimposed on the PTCER images. As no systematic slice to slice or side to side differences were present, a single mean value per subject was calculated. Representative tomographic images of PTCER from one nonRDS infant and one RDS infant are also shown.

The in vivo binding of ${ }^{68} \mathrm{Ga}$ to transferrin was measured in three infants. Two hundred microlitres of serum, obtained 10 minutes after injection of the tracer, were centrifuged at $1000 \times g$ in a Centrifree micro-partition tube (Amicon Inc., Beverly, MA) with a 30000 molecular weight cutoff filter. A gamma counter then measured the fraction of ${ }^{68} \mathrm{Ga}$ which was bound to proteins with molecular weight > 30 000. For these three infants, 99.7 (0.3)\% of the ${ }^{68} \mathrm{Ga}$ was protein bound.

Repeated measures analysis of variance using the Statistical Analysis System for PC based systems (SAS, Inc., Cary, NC) was performed to evaluate differences between mean values. Results are expressed as mean (SD). Correlations between variables were analysed using standard linear regression methods, also with SAS. $P \leqslant 0.05$ was regarded as significant.

\section{Results}

The clinical and PTCER data for the infants without RDS are given in table 1 . Their gestational ages ranged from 28 to 40 weeks and age at the time of PET scan ranged from 12 to 90 hours. Infants 11 and 12 were mechanically ventilated at the time of the scan. The mean (SD) PTCER for this group was 75 (27) $10^{-4} / \mathrm{min}$ (fig 2). To determine whether PTCER was influenced by gestational age or chronological age, we compared the PTCER measurements between non-RDS infants who were less than 37 weeks gestation with those who were 37 weeks gestation or greater. We also compared measurements between infants who were 24 hours of age or less with those 
Table 1 Clinical and PET data for non-RDS infants

\begin{tabular}{|c|c|c|c|c|c|}
\hline No & $\begin{array}{l}\text { Birthweight } \\
\text { diagnosis }\end{array}$ & Weight $(g)$ & Age (weeks) & $\begin{array}{l}\text { Age at the time of } \\
\text { PET scan (h) }\end{array}$ & PTCER $10^{-4} / \mathrm{min}$ \\
\hline 1 & Preterm & 1015 & 28 & 40 & 84 \\
\hline 2 & Preterm & 1240 & 30 & 90 & 81 \\
\hline 3 & Preterm & 1650 & 32 & 24 & 38 \\
\hline 4 & Preterm & 1700 & 33 & 22 & 142 \\
\hline 5 & Preterm & 2150 & 33 & 24 & 87 \\
\hline 6 & Preterm & 2300 & 33 & 25 & 97 \\
\hline 7 & Preterm & 1460 & 34 & 72 & 64 \\
\hline 8 & Preterm & 2165 & 35 & 14 & 37 \\
\hline 9 & Smal VSD & 3090 & 36 & 24 & 55 \\
\hline 10 & $\begin{array}{l}\text { Intrauterine } \\
\text { growth } \\
\text { retardation }\end{array}$ & 2185 & 38 & 35 & 69 \\
\hline 11 & HLHS & 3435 & 38 & 78 & 70 \\
\hline 12 & $\begin{array}{l}\text { Subdural } \\
\text { haematoma } \\
\text { and seizure }\end{array}$ & 2710 & 40 & 18 & 102 \\
\hline 13 & TOGV & 3660 & 40 & 54 & 47 \\
\hline 14 & TTN & 5585 & 40 & 12 & 76 \\
\hline Mean (SD) & & $2.45(1.2) \mathrm{kg}$ & $35(4)$ & $38(25)$ & $75(27)$ \\
\hline
\end{tabular}

VSD = ventricular septal defect; HLHS = hypoplastic left heart syndrome;

TOGV = transposition of the great vessels; TTN = transient tachypnoea of the newborn.

who were greater than 24 hours of age (data not shown). No differences in PTCER were found with any of these comparisons.

The clinical and PTCER data for the RDS infants are presented in table 2 . All infants with RDS were less than 37 weeks of gestation, 24 hours of age or less, and were receiving conventional mechanical ventilation (except one infant who was receiving nasal cannula oxygen). Infants did not require pharmacological support for blood pressure nor had they clinical evidence of a patent ductus arteriosus. One infant was extubated by the time of the second scan.

Individual PTCER data are presented in fig 2. The mean PTCER for the 12 RDS infants at the first measurement was 132 (39) $10^{-4} / \mathrm{min}$, which was significantly greater than the mean PTCER for the non-RDS infants $(p=0.001)$. PTCER for the RDS infants was also significantly greater than that for the nine non-RDS infants who were less than 37 weeks of gestation $(p=0.003)$. Individual changes in PTCER occurred between the two scans, but as a group, these were not significant $(p=0.07)$ (fig 2). The arterial:alveolar oxygen ratio did not change significantly $(\mathrm{p}=0.25)$. For the five infants who received surfactant, the a:A ratio increased by $70 \%(p=0.05)$, but the mean PTCER did not change between the two scans (149 (41) to $\left.200(18) 10^{-4} / \mathrm{min} ; \mathrm{p}=0.08\right)$.

In infants with RDS, PTCER did not correlate with gestational age, severity of disease on chest radiograph, mean airway pressure, or the a:A ratio. For individual infants, the change in PTCER did not correlate with the change in a:A ratio (data not shown). All study infants survived and none required supplemental oxygen at 28 days of life.

\section{Discussion}

This study represents the first application of PET to evaluate pulmonary vascular permeability in human neonates. Previous studies in adults and mature animals have demonstrated the structure-function correlations that support the PET measurement of PTCER. ${ }^{9}{ }^{10} \mathrm{We}$ were unable to make histological correlates in this current study, but the similarity of our PET physiological measurements to these previous studies suggests the feasibility of applying this technique to neonates.

Differences in pulmonary circulatory physiology between neonates and adults should not affect the PET measurement of PTCER. First, although pulmonary vascular permeability is influenced by the vascular surface area available for exchange, the PTCER is normalised for blood volume, a marker of surface area, thus taking into account the difference in vascular surface area between neonates and adults. Second, pulmonary blood flow and tracer delivery to the lungs may be different between neonates and adults. Under normal conditions, the vascular concentration of radioisotope is independent of pulmonary blood flow unless the perfusion is severely compromised. ${ }^{1213}$ Under these conditions, which can be detected by examination of the individual time-activity curves, blood volume is underestimated, leading to an overestimation in PTCER. All time-activity curves suggested that the equilibrium state for tracer delivery was achieved by the start of the scans. For these same reasons, blood flow through a patent ductus arteriosus would not affect

Table 2 Clinical and PET data for infants with RDS

\begin{tabular}{|c|c|c|c|c|c|c|c|c|c|c|c|}
\hline \multirow[b]{2}{*}{ No } & \multirow[b]{2}{*}{ Weight $(g)$} & \multirow{2}{*}{$\begin{array}{l}\text { Gestational } \\
\text { age (weeks) }\end{array}$} & \multirow[b]{2}{*}{ Race } & \multirow[b]{2}{*}{ Sex } & \multirow{2}{*}{$\begin{array}{l}\text { Age at scan } \\
1 \text { (h) }\end{array}$} & \multirow[b]{2}{*}{ Surfactant } & \multicolumn{2}{|c|}{ a:A ratio ${ }^{\star}$} & \multirow[b]{2}{*}{ Radiography } & \multicolumn{2}{|c|}{$\begin{array}{l}P T C E R \\
\left(10^{-4} / \mathrm{min}\right)\end{array}$} \\
\hline & & & & & & & Scan 1 & Scan 2 & & Scan 1 & Scan 2 \\
\hline 15 & 1000 & 26 & B & $M$ & 3 & $\mathrm{~N}$ & 0.59 & 0.26 & Moderate & 125 & 80 \\
\hline 16 & 930 & 27 & W & $\mathrm{F}$ & 8 & $\mathrm{~N}$ & $t$ & $t$ & Mild & 147 & 119 \\
\hline 17 & 1020 & 29 & W & M & 13 & $\mathrm{~N}$ & $t$ & $t$ & Mild & 71 & 61 \\
\hline 18 & 1495 & 30 & B & $\mathrm{F}$ & 10 & $\mathrm{~N}$ & 0.26 & 0.26 & Mild & 121 & 130 \\
\hline 19 & 2400 & 35 & W & $\mathrm{F}$ & 17 & $\mathrm{~N}$ & $t$ & $t$ & Mild & 146 & $\ddagger$ \\
\hline 20 & 2450 & 35 & W & M & 7 & $\mathrm{~N}$ & 0.35 & 0.66 & Mild & 71 & 149 \\
\hline 21 & 2600 & 35 & W & $M$ & 14 & $\mathrm{~N}$ & 0.19 & 0.18 & Severe & 161 & 162 \\
\hline 22 & 940 & 27 & W & $M$ & 9 & $\mathrm{Y}$ & 0.49 & 0.46 & Mild & 225 & 192 \\
\hline 23 & 1420 & 31 & W & $\mathrm{F}$ & 8 & $\mathrm{Y}$ & 0.14 & 0.45 & Severe & 142 & 216 \\
\hline 24 & 2178 & 35 & W & $\mathrm{F}$ & 21 & $\mathrm{Y}$ & 0.18 & 0.31 & Moderate & 103 & 174 \\
\hline 25 & 2800 & 35 & W & $\mathrm{F}$ & 18 & $\mathrm{Y}$ & 0.13 & 0.29 & Severe & 129 & $\ddagger$ \\
\hline 26 & 2735 & 36 & W & M & 22 & $\mathrm{Y}$ & 0.16 & 0.36 & Moderate & 145 & 219 \\
\hline $\begin{array}{l}\text { Mean } \\
\text { (SD) }\end{array}$ & $\begin{array}{l}1.8 \\
(0.8) \mathrm{kg}\end{array}$ & $\begin{array}{l}32 \\
(4)\end{array}$ & & & $\begin{array}{l}12 \\
(6)\end{array}$ & & $\begin{array}{l}0.28 \\
(0.16)\end{array}$ & $\begin{array}{l}0.36 \\
(0.14)\end{array}$ & & $\begin{array}{l}132 \\
(39)\end{array}$ & $\begin{array}{l}160 \\
(45)\end{array}$ \\
\hline
\end{tabular}

$\star$ a:A ratio $=$ arterial-alveolar oxygen ratio: $\mathrm{P}_{\mathrm{a}} \mathrm{O}_{2} /\left[\mathrm{FiO}_{2}(713)-\mathrm{P}_{\mathrm{a}} \mathrm{CO}_{2}\right]$.

† Arterial blood gases not available.

$\ddagger$ Only one scan performed.

$\mathrm{CXR}=$ chest radiograph - mild disease, granular appearance - moderate disease, air bronchograms - severe disease, opacification of lung field. 
interpretation of the measurements. Thus methodological issues arising with performing PET measurements of pulmonary vascular permeability should not be affected by physiological differences between neonates and mature humans or animals.

The PTCER values for infants with RDS were comparable with those for adults with ARDS, pneumonia, and interstitial lung disease using similar techniques. ${ }^{6714}$ In preterm infants with RDS, a quantitative deficiency of surfactant may lead to secondary disruption of the endothelial-epithelial barrier. The studies of Jefferies et al, mentioned previously, as well as the identification of surfactant protein-A (molecular weight 35000 Daltons) in the blood of premature infants with RDS provide evidence for loss of integrity of the alveolar epithelial-endothelial barrier and net flux from alveolus to vascular space. ${ }^{4}{ }^{15}$ In addition, studies in preterm lambs with RDS have shown a bidirectional leak of radiolabelled albumin. ${ }^{2}$ Indirectly, the presence of hyaline membranes, on histological examination of lung tissue, suggests a vascular-alveolar protein leak. To our knowledge, our PET studies are the first in vivo measurements in humans which demonstrate net protein flux from the vascular to the extravascular space.

Those infants with RDS who received surfactant showed an improvement in oxygenation following treatment that was not reflected by a decrease in the PTCER. However, previous studies in which premature lambs treated early with surfactant had lower pulmonary vascular permeability than untreated lambs suggested that surfactant treatment may have a direct influence on pulmonary vascular permeability. ${ }^{16} 17$ These observations taken together suggest that surfactant treatment may prevent the endothelial or epithelial injury which initiates the protein leak, but surfactant does not attenuate the leak once it has occurred, perhaps explaining the failure of surfactant treatment in some infants with RDS. ${ }^{18}$

The PET measurement of PTCER provides a non-invasive method for evaluating lung injury that may be associated with increased pulmonary vascular permeability. Animal studies have suggested a correlation between PTCER and histological or ultrastructural indices of lung injury. ${ }^{9}{ }^{10}$ However, human studies, ours included, have not shown a correlation between PTCER and clinical indices of disease severity. These clinical indices are a reflection of the degree and duration of vascular leak, the presence of atelectasis, and ventilation-perfusion relations, among others.
Thus the development of additional metabolic tracers should permit a comprehensive in vivo evaluation of other physiological processes that may contribute to newborn pulmonary dysfunction and will help delineate mechanisms of lung injury and response to treatment.

An abstract based on these data was presented at the Society for Pediatric Research Meeting, 2-5 May 1994 (Pediatr Res 1994;35:346A).

This work was supported in part by a grant from the American Lung Association of Eastern Missouri (AH).

We thank Drs Daniel P Schuster and F Sessions Cole for their thoughtful comments, Dr Barry Siegel for access to the clinical PET facility, and Dawn Rouse for secretarial assistance.

1 Whitsett JA, Pryhuber GS, Rice WR, Warner BB, West SE. Acute respiratory disorders. In: Avery GB, Fletcher MA, Macdonald MG, eds. Neonatology - pathophysiology and management of the newborn. Philadelphia: J.B.Lippincott, 1994:429-52.

2 Jobe A, Jacobs H, Ikegami M, Berry D. Lung protein leaks in ventilated lambs: effect of gestational age. 7 Appl Physiol 1985;58:1246-51.

3 Bland RD, Carlton DP, Scheerer RG, Cummings JJ, Chapman DL. Lung fluid balance in lambs before and after premature birth. $\mathcal{F}$ Clin Invest 1989;84:568-76. 4 Jefferies AL, Coates G, O'Brodovich H. Pulmonary epithe-
lial permeability in hyaline-membrane disease. $N$ Engl $\mathcal{F}$ Med 1984;311:1075-80.

5 MacGillivry RTA, Mendez E, Sinha SK, Sutton MR, Lineback - Zins J, Brew K. The complete amino acid sequence of human transferrin. Proc Natl Acad Sci USA 1982;79:2504-8.

6 Calandrino FS, Anderson DJ, Mintun MA, Schuster DP. Pulmonary vascular permeability during the adult respiratory distress syndrome: A positron emission tomographic study. Am Rev Respir Dis 1988;138:421-8.

7 Kaplan JD, Calandrino FS, Schuster DP. A positron emission tomographic comparison of pulmonary vascular permeability during the adult respiratory distress syndrome and pneumonia. Am Rev Respir Dis 1991;143:1504.

8 Kirpalani H, Abubbakar K, Nahmias C, DeSa D, Coates G, Schmidt B. [18F]Fluorodeoxyglucose uptake in neonatal acute lung injury measured by positron emission tomograacute lung injury measured by pos
phy. Pediatr Res 1997;41:892-6.

9 Velazquez M, Weibel ER, Kuhn C, Schuster DP. PET evaluation of pulmonary vascular permeability: A structure-function correlation. $\mathcal{F}$ Appl Physiol 1991;70:2206-16.

10 Hamvas A, Palazzo R, Kaiser L, et al. Inflammation and oxygen free radical formation during pulmonary ischemiareperfusion injury. F Appl Physiol 1992;72:621-8.

11 Cooper JA, Malik AB. Pulmonary transvascular flux of transferrin. F Appl Physiol 1989;67:1850-4.

12 Mintun MA, Dennis DR, Welch MJ, Mathias CJ, Schuster DP. Measurement of pulmonary vascular permeability with PET and gallium-68 transferrin. F Nucl Med 1987;28:1704-16.

13 Hamvas A, Kaplan JD, Markham J, Schuster DP. The effects of regional pulmonary blood flow on protein flux measurements with PET. $\mathcal{F}$ Nucl Med 1992;33:1661-8.

14 Kaplan JD, Trulock EP, Anderson DJ, Schuster DP. Pulmonary vascular permeability in interstitial lung disease A positron emission tomographic study. Am Rev Respir Dis 1992; 145:1495-8

15 Chida S, Phelps DS, Soll RF, Taeusch HW. Surfactant proteins and anti-surfactant antibodies in sera from infants with respiratory distress syndrome with and without surfactant treatment. Pediatrics 1991;88:84-9.

16 Ikegami M, Jobe AH, Tabor BL, Rider ED, Lewis JF. Lung albumin recovery in surfactant-treated preterm ventilated lambs. Am Rev Respir Dis 1992;145:1005-8.

17 Carlton DP, Cho SC, Davis P, Lont M, Bland RD. Surfactant treatment at birth reduces lung vascular injury Surfactant treatment at birth reduces lung vascular injury
and edema in preterm lambs. Pediatr Res 1995;37:265-70.

18 Hamvas A, Devine T, Cole FS. Surfactant therapy failure identifies infants at risk for pulmonary mortality. Am $\mathcal{F} \mathrm{Dis}$ Child 1993;147:665-8 